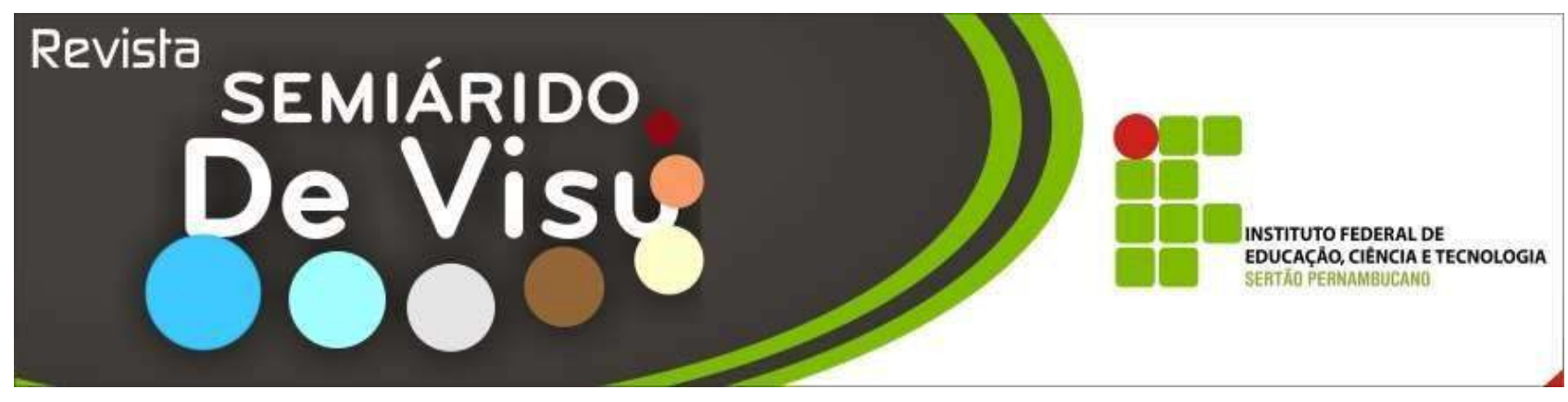

\title{
Utilização de farinha de resíduos do abate em dietas para a tilápia do Nilo
}

\author{
Carla Samantha Rodrigues Silva Valério ${ }^{1}$, Henrique José Torres de Santana ${ }^{2}$, Renilde Cordeiro de \\ Souza $^{3}$, Maria da Conceição Aquino de Sá ${ }^{4}$
}

${ }^{1,2}$ Instituto Federal de educação, ciência e tecnologia do Sertão-PE, Campus Petrolina Zona Rural, Rodovia BR 235, km 22, Projeto Senador Nilo Coelho - N4, CEP 56.300-000, (87) 2101-8050, Petrolina - PE

${ }^{3}$ Universidade Federal da Bahia, Av. Adhemar de Barros, 500 - Ondina, CEP 40170- (71) 3283-6707, Salvador- BA

${ }^{4}$ Universidade Federal do Vale do São Francisco, Laboratório de Microbiologia e Imunologia Animal, Rodovia BR-407 Km 12, Lote 543, Projeto de Irrigação Senador Nilo Coelho s/n, C1, Petrolina, PE 56300-990, Brasil

${ }^{1}$ carla.samantha@ifsertao-pe.edu.br;

Resumo: A piscicultura contribui para produção de alimento com alto valor biológico ao homem. O uso de ingredientes alternativos para alimentação de peixes é válido, desde que obedeça a níveis seguros de inclusão de seus nutrientes e da presença de microrganismos, disponibilidade regional e viabilidade econômica. A farinha de resíduos do abate animal representa um ingrediente com potencial para utilização na fabricação de rações para peixes, devido ao seu elevado valor proteico e baixo custo. Com o objetivo de avaliar a qualidade da farinha de resíduos do abate de caprinos, ovinos e bovinos em dietas para a tilápia do Nilo, análises bromatológica e microbiológica foram realizadas. Uma ração base foi formulada, podendo-se estabelecer percentuais de inclusão do ingrediente teste nas rações. Pretende-se avaliar a qualidade nutricional e microbiológica deste ingrediente a fim de contribuir com a redução no custo das rações, obtenção de desempenho semelhante ou superior nos peixes alimentados com ingredientes alternativos e ainda, a diminuição do desperdício e poluição ambiental por resíduos gerados a partir do abate de animais.

Palavras-chave: Farinha de origem animal, desempenho, Oreochromis niloticus.

\section{Use flour slaughter waste in diets for Nile tilapia}

\begin{abstract}
Aquaculture contributes to food production with high biological value to man. The use of alternative ingredients for fish feed is valid if it satisfies the safe levels of inclusion of its nutrients and the presence of microorganisms, regional availability and economic viability. The flour of animal slaughter waste is an ingredient with potential for use in the manufacture of fish feed because of its high protein value and low cost. In order to assess the quality of the flour waste of slaughter goats, sheep and cattle in diets for Nile tilapia, bromatological analysis and microbiological were performed. A basic diet was formulated; it can be established percentage of inclusion of test ingredient in feed. It aims to assess the nutritional and microbiological quality of this ingredient in order to contribute to the reduction in the cost of feed, obtaining equal or better performance in fish fed with alternative ingredients and also reducing waste and environmental pollution by waste generated from slaughter of animals.
\end{abstract}

key words: Flour of animal origin, performance, Oreochromis niloticus. 
(VALÉRIO et al., 2016)

\section{INTRODUÇÃO}

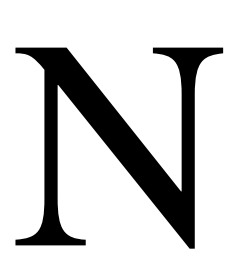

o Brasil, a aquicultura, em especial a piscicultura, consolidou-se como atividade zootécnica importante no aspecto socioeconômico e ambiental através de vários fatores, dos quais podemos citar a grande disponibilidade $\mathrm{e}$ qualidade de água, além de uma variedade de espécies de peixes adaptadas a diferentes condições climáticas.

A piscicultura nacional vem se constituindo com sistemas de cultivo intensivo e super intensivo. Intensificar um cultivo implica em aumentar a quantidade de biomassa por área, à custa do fornecimento constante de alimento balanceado. Os ingredientes que compõem estas dietas possuem um elevado aporte proteico contribuindo com o alto custo com alimentação que pode atingir até $60 \%$ do custo total (GOMES et al., 2006), desta forma, a alimentação tornou-se o fator unitário mais importante na administração dos cultivos modernos. Assim, o conhecimento acerca da nutrição de peixes é um dos fatores importantes, priorizando a busca por alimentos alternativos que possam substituir os ingredientes tradicionais com consequente redução dos custos é de extrema importância para a sustentabilidade da criação de peixes.

Segundo Paiva (2010), além da determinação dos níveis, práticos e seguros, de inclusão de ingredientes alternativos, deve-se considerar a disponibilidade regional, e a viabilidade econômica. Nesse contexto, a farinha de resíduos de abatedouro apresenta-se como um ingrediente potencial para utilização na fabricação de rações para peixes. Este é considerado o principal subproduto de abatedouro utilizado na nutrição animal, sendo uma excelente fonte proteica, apresentando teores de proteína bruta entre 35 e $55 \%$ e importante fonte de cálcio e fósforo (VIEITES et al.,1999).

Segundo Bellaver e Zanotto (2004), a Farinha de carne e ossos mista (FCOM) é produzida em graxarias por coleta de resíduos, ou em frigoríficos a partir de ossos e tecidos, após a desossa completa da carcaça de bovinos e/ou ovinos e/ou suínos; moídos, cozidos, prensados para extração de gordura e novamente moídos, sem conter sangue, cascos, unhas, chifres, pelos, conteúdo estomacal a não ser os obtidos involuntariamente dentro dos princípios de boas práticas de fabricação.

A farinha de carne e ossos, por ser um alimento de origem animal, possui grandes quantidades de proteína, ácidos graxos, minerais e vitaminas, porém é necessário analisar esses alimentos quanto ao seu teor de contaminação. Assim, a qualidade da farinha pode afetar o desempenho dos peixes.

Alimentos processados em abatedouros requerem bastante atenção, já que podem ser fabricados com resíduos de fezes e outras sujidades, que normalmente contém microorganismos diversos a exemplo de protozoários, fungos e bactérias. É necessário verificar se o teor de microrganismo pode afetar a qualidade do alimento. Assim a matéria prima das rações dos animais precisa ser monitorada para que não ofereça produtos que possam prejudicar a saúde do animal e ao mesmo tempo, que possa oferecer nutrientes para o melhor desempenho (CUSTODIO et al., 2005).

A farinha de resíduos do abate de caprinos, ovinos e bovinos já tem sido utilizada na região do Vale do São Francisco em rações para aves, entretanto pouco se sabe sobre influencia desta em dietas para peixes principalmente sobre o desempenho dos animais. Dessa forma, o objetivo deste trabalho foi avaliar a farinha de resíduos do abate de caprinos, ovinos e bovinos, produzida no abatedouro municipal de Petrolina-PE, quanto ao seu perfil bromatológico e microbiológico para utilização em dietas para a tilápia do Nilo.

\section{MATERIAL E MÉTODOS}

O presente estudo foi realizado pelo Laboratório de Piscicultura do Instituto Federal de Educação, Ciência e Tecnologia do Sertão Pernambucano, Campus Petrolina-PE zona rural (IF Sertão-PE), em parceria com Laboratório de Análise de Alimentos do SEBRAE, Petrolina-PE, Laboratório de 
(VALÉRIO et al., 2016)

Análise de Alimentos da Universidade Federal do Vale do São Francisco (UNIVASF), Campus Ciências Agrárias e Laboratório de Microbiologia e Imunologia Animal da UNIVASF, Campus Ciências Agrárias, Petrolina-PE, nos quais foram realizadas as análises bromatológicas e microbiológicas, respectivamente, durante o período de maio de 2013 a março de 2014.

\section{Bromatologia}

As análises bromatológicas foram realizadas para obtenção da composição química dos alimentos, determinando, assim, as frações nutritivas do mesmo. Para isso, foram coletadas três amostras compostas de farinha de carne e ossos (FCO) em abatedouro municipal de Petrolina-PE, em seguida foram acondicionadas e armazenadas em potes plásticos e encaminhadas ao laboratório para realizar as seguintes análises: Umidade: Evaporação em estufa à $105^{\circ} \mathrm{C}\left(55,65^{\circ} \mathrm{C}\right.$ e depois $105^{\circ} \mathrm{C}$ ); Matéria Seca: 100 - água; Matéria Orgânica: Matéria seca - cinzas; Cinzas: incineração do alimento em muflaa $600^{\circ} \mathrm{C}$; Proteína Bruta: determina, o nitrogênio total, cujo valor é multiplicado pelo fator 6,25 ; Nitrogênio: Isolamento e quantificação do $\mathrm{N}$ na forma de amônia, por digestão, destilação e titulação; Fibra Bruta: fervura em álcalis e ácidos fracos; Energia Bruta: ENN: 100 $($ Água + PB + FB + EE + MM) e Extrato etéreo: extração com éter.

Os resultados do laboratório representam a composição do lote onde a amostra foi retirada, dessa forma, como o material analisado é produzido a partir do resíduo de abate de diferentes espécies (caprino, ovino e bovino), por isso chamada de farinha carne e ossos mista (FCOM), o resultado destas análises representa um determinado lote, podendo, outros lotes apresentarem diferentes teores de alguns nutrientes, a depender da quantidade de cada material contido na mistura.

É importante ressaltar, também que, como foi descrito por Andrigueto et al. (1988a), os ossos provenientes de animais jovens são mais moles e elásticos do que aqueles oriundos de animais adultos e que por isso, a composição de substâncias minerais na farinha de carne e ossos, pode variar conforme as idades dos animais abatidos.

\section{Microbiologia}

Foram coletadas quatro amostras compostas de farinha de carne e ossos no abatedouro municipal de Petrolina-PE, em seguida foram acondicionadas e armazenadas em sacos plásticos para realizar as seguintes análises microbiológicas:

\section{Contagem de Coliformes Totais, Coliformes Termotolerantes e Escherichia coli}

\section{Método do Número Mais Provável (NMP) - Coliformes Totais e Termotolerantes}

Assim foram pesados $25 \mathrm{~g}$ de cada amostra e colocada em $225 \mathrm{~mL}$ de água peptonada tamponada. Após homogeneização da amostra, foi efetuada as diluições em dois tubos de $9 \mathrm{~mL}$ de água peptonada, considerando a diluição inicial $10^{-1}$. Para em seguida fazer a diluição em tubos de ensaio com tubos de durhan, contendo $10 \mathrm{~mL}$ de caldo Lauril sulfato de sódio nas diluições $10^{-1}, 10^{-2}$ e $10^{-3}$, após incubar por 24 horas a $37^{\circ} \mathrm{C} \pm 1$ em aerobiose. Essa metodologia foi realizada em triplicata.

\section{Contagem de Termotolerantes e Escherichia coli}

Após 24 horas de incubação no caldo Lauril, as diluições que obtiveram resultados positivos, foram inoculados em tubos de ensaio com tubos de durhan contendo $10 \mathrm{~mL}$ de caldo $E$. coli cada, em uma série de 3 tubos, sendo incubados em banho Maria com agitação de água a $41^{\circ} \mathrm{C} \pm 1$ por 24 horas em aerobiose. Os tubos positivos foram semeados com $10 \mu \mathrm{L}$ através de estria de esgotamento em placas contendo Ágar Macconkey. Após a semeadura, as placas foram incubadas a $37 \pm 1^{\circ} \mathrm{C}$ por 24 horas em aerobiose. Em seguida foi realizada 
a leitura e colônias sugestivas para Escherichia coli sendo isoladas em Ágar Triptose de soja (TSA).

\section{Método de Contagem Total de Aeróbios Mesófilos em Placas}

A partir das diluições em água peptonada tamponada, nas diluições $10^{-1}, 10^{-2}$ e $10^{-3}$. Foram semeados $0,1 \mathrm{~mL}$ de cada diluição em placas de Petri estéreis contendo cerca de 20 mL de Plate Count Agar (PCA) realizando o espalhamento com auxílio de alça de Drigalski de vidro. As placas foram incubadas a $37 \pm 1^{\circ} \mathrm{C}$ por 24 horas em aerobiose para posterior contagem de colônias presentes. O ensaio foi realizado em triplicata.

\section{Pesquisa para Salmonella}

\section{Pré-enriquecimento}

Foi realizado o pré-enriquecimento com 225 $\mathrm{mL}$ de água peptonada tamponada, adicionando-se $25 \mathrm{~g}$ da amostra. Depois foi incubado a $37 \pm 1^{\circ} \mathrm{C}$ por 18 horas em incubador tipo Shaker com circulação.

\section{Enriquecimento seletivo}

Depois de incubado a amostra foi transferida $0,1 \mathrm{~mL}$ para $10 \mathrm{~mL}$ de caldo RappaportVassilidis Soja e $1 \mathrm{~mL}$ pra $10 \mathrm{~mL}$ de caldo Tetrationato Muller. O caldo Rappaport foi incubado em banho Maria a $41 \pm 1^{\circ} \mathrm{C}$ por 24 horas e o caldo Tetrationatofoi incubado a $37 \pm$ $1^{\circ} \mathrm{C}$ por 24 horas em aerobiose.

\section{Plaqueamento diferencial}

Da cultura em Rappaport foi semeada $10 \mu \mathrm{L}$ através de estria de esgotamento em 03 meios diferenciais: Ágar Xilose Lisina Desoxicolato (XLD), Ágar Hektoen Enteric (Agar HE) e Ágar Samonella Shiguella (SS). Após a semeadura, as placas foram incubadas a $37 \pm$ $1^{\circ} \mathrm{C}$ por 24 horas em aerobiose. Em seguida foi realizada a leitura e colônias sugestivas para Salmonella spp. sendo isoladas em Ágar Triptose de soja (TSA).

\section{Contagem de Staphylococcus spp.}

Foi inoculada a amostra em quatro placas, sendo três com $0,3 \mathrm{~mL}$ e uma com $0,1 \mathrm{~mL}$ e incubadas a $35-37^{\circ} \mathrm{C}$ em aerobiose por $24 \mathrm{~h}$. O inoculo foi espalhado com alça de Drigalski. As colônias típicas de Staphylococcus foram contadas, as que forem circulares, pretas ou cinza, rodeadas por uma zona opaca e/ou halo transparente.

\section{Método de Contagem Total de Bolores e leveduras em placas}

A partir das diluições em água peptonada tamponada, nas diluições $10^{-1}, 10^{-2}$ e $10^{-3}$. Foram semeados $0,1 \mathrm{~mL}$ de cada diluição em placas de Petri estéreis contendo cerca de 20 $\mathrm{mL}$ de ágar Batata Dextrose (BDA) realizando o espalhamento com auxílio de alça de Drigalski de vidro, flambadas. A incubação das placas foi a $25 \pm 1{ }^{\circ} \mathrm{C}$ por 120 horas em aerobiose para posterior contagem de colônias presentes. Realizando leituras a cada 24 horas para verificar o crescimento de colônias. O ensaio foi realizado em triplicata.

\section{Método de Contagem Total de Clostrídios em placas}

A partir das diluições em água peptonada tamponada, nas diluições $10^{-1}, 10^{-2}$ e $10^{-3}$. Foram semeados $1 \mathrm{~mL}$ de cada diluição em placas de Petri com $20 \mathrm{~mL}$ de Reinforced Agar clostridiol (RCA) realizando o espalhamento com auxílio de alça de Drigalski de vidro. Após semeadura as placas foram incubadas em jarra de anaerobiose a $37 \pm 1^{\circ} \mathrm{C}$ por 24 horas para posterior contagem de colônias presentes. $\mathrm{O}$ ensaio foi realizado em triplicata.

\section{Coloração de Gram}

As amostras isoladas em TSA foram submetidas a coloração de Gram de acordo com Quin et al. (1994). 
(VALÉRIO et al., 2016)

\section{Testes bioquímicos}

Foi realizada a identificação presuntiva através dos testes em Ágar Tríplice Açúcar Ferro (TSI), teste de indol, teste de motilidade, Ágar Citrato de Simmons, glicose oxidativa fermentativa (GOF), teste de Uréia, teste de glicose, maltose, esculina e nitrato.

\section{RESULTADOS E DISCUSSÕES}

Segundo a Instrução Normativa $n^{\circ} 34$, de 28 de maio de 2008, do Ministério de estado da agricultura, pecuária e abastecimento, é proibida a utilização de pelos, cerdas, cascos, chifres, sangue, fezes, conteúdo estomacal, resíduos animais abatidos em estabelecimentos não autorizados e materiais especificados de risco (MER), como resíduos animais para o processamento de farinhas de carne e/ou ossos ou produtos gordurosos. Dessa forma a realização dessas análises possibilita o conhecimento da qualidade do ingrediente em questão, indicando se o mesmo atende as normas legais exigidas para sua fabricação e comercialização.

Bromatologia
A farinha de carne e osso tem sido frequentemente estudada como alimento alternativa em rações para animais de produção. No caso dos peixes, quando utilizada, reduz o custo das rações, por substituir a farinha de peixes, bem como permite a destinação adequada para este subproduto dos abatedouros. No entanto, seu uso deve ser controlado, por conter teores, muitas vezes desconhecido de minerais. Devido ao fato de que os valores nutricionais das farinhas de carne e ossos podem variar conforme a idade do animal, as espécies abatidas e à observância das boas práticas de fabricação presentes na legislação.

Segundo Vieites et al. (1999), os teores de proteína bruta podem variar entre 35 e $55 \%$, em farinha de carne e ossos enquanto que o cálcio não deve exceder a 2,5 vezes o nível de fósforo (BELLAVER e ZANOTTO, 2004).

$\mathrm{Na}$ tabela 1 é possível observar os valores referentes a analise bromatológica da Farinha de carne e ossos mista e os valores de referência citados por Rostagno (2000), quanto às farinhas de carne e ossos com valores de proteína variando entre 55 e $60 \%$.

Tabela 1: Valor nutricional da Farinha de carne e ossos mista.

\begin{tabular}{lcc}
\hline \multirow{2}{*}{ NUTRIENTE } & \multicolumn{2}{c}{ Farinha de carne e ossos mista $($ FCOM) } \\
\cline { 2 - 3 } & Valor encontrado & Valor de referência* \\
\hline Cálcio & $39,8(\mathrm{mg} / \mathrm{g})$ & 8,46 a $7,98 \%$ \\
Fósforo & $0,21(\mathrm{mg} / \mathrm{g})$ & 4,18 a $3,90 \%$ \\
Proteína bruta & $58,47 \%$ & 54,50 a $61,28 \%$ \\
Energia bruta & $3.074\left(\mathrm{KCal} / \mathrm{kg}_{-}{ }^{-1}\right)$ & $4.145 \mathrm{a} 4.341\left(\mathrm{KCal} / \mathrm{kg}^{-1}\right)$ \\
FDN & $33,43 \%$ & - \\
FDA & $22,82 \%$ & - \\
Fibra bruta & - & 1,50 a $0,94 \%$ \\
MM & $14,25 \%$ & 23,18 a $19,92 \%$ \\
MS & $94,58 \%$ & 92,71 a $92,14 \%$ \\
Extrato etério & $9,96 \%$ & 08 a $16 \%$ \\
\hline *Especificações para farinha de carne e ossos segundo Rostagno, $(2000)$.
\end{tabular}

Santos et al. (2014), analisando resíduo de abate de caprinos e ovinos, verificou um valor de 25,79\% de proteína bruta e 4.635,64 Kcal de energia bruta. Vale salientar que as 
diferenças de valores presentes na literatura podem ser devidas às variações nas proporções de partes dos animais, bem como espécies e idade dos animais.

É possível observar que, a FCOM avaliada, apresenta bom valor proteico $\mathrm{e}$ energético, elevado teor de matéria seca, o que indica baixa umidade, permitindo maior validade do produto e relação $\mathrm{Ca}: \mathrm{P}$, dentro dos padrões.

Santos et al. (2009) observaram que a farinha de resíduo caprino/ovino (sem ossos) possui um elevado valor proteico $(75,14 \%)$, além de um valor energético de 5857,34 $\mathrm{Kcal} / \mathrm{Kg}$ de ração. Estes autores observaram ainda altos valores de digestibilidade da proteína bruta e energia, caracterizando-a como um ingrediente de grande potencial para utilização em dietas para tilápia do Nilo.

Santos, et al. 2014, também observou uma boa digestibilidade de rações elaboradas com resíduos de abates de caprinos e ovinos, significando que poderemos encontrar bons resultados para o uso desta farinha de carne e ossos analisada no presente trabalho.

Tabela 2: Formulação de ração teste para futura avaliação de digestibilidade e desempenho de peixes alimentados com rações contendo farinha de resíduos de abate em substituição a farinha de peixe.

\begin{tabular}{cc}
\hline ALIMENTO & QUANTIDADE (\%) \\
\hline Milho grão & 40,00 \\
Soja farelo 45\% & 39,28 \\
FCO & 14,16 \\
Óleo de soja & 2,81 \\
Fosfato bicálcico & 1,5 \\
Minerais-peixes & 0,8 \\
Inerte & 0,72 \\
Sal comum & 0,5 \\
Vitamina C - peixe & 0,1 \\
Antifúngico & 0,1 \\
Antioxidante & 0,02 \\
\hline
\end{tabular}

Diversos trabalhos têm demonstrado a FCO como um ingrediente de excelente valor nutricional, no que diz respeito às quantidades de proteína e energia, bem como a relação $\mathrm{Ca}: \mathrm{P}$, porém, existem algumas recomendações quanto à limitação do seu uso, uma vez que os teores de minerais podem interferir na digestibilidade da ração, conforme descrito por Signor et al. (2010). Dessa forma, posteriormente a este estudo, diferentes níveis de inclusão deste ingrediente serão testados para alimentação de peixes.

\section{Microbiologia}

A partir do teste para coliformes totais foi possível observar a seguinte resultado na tabela 3:

Tabela 3: Leitura de coliformes totais realizado em caldo Lauril, considerando (+) positivo e (-) negativo para formação de gás. 
(VALÉRIO et al., 2016)

\begin{tabular}{cccc}
\hline Amostra & $\begin{array}{c}\text { Combinação de } \\
\text { Tubos }+\end{array}$ & NMP/g & Resultado \\
\hline A & 3.2 .2 & 20 & 21,37 \\
B & 3.2 .1 & 17 & 18,35 \\
C & 3.3 .0 & 17 & 18,09 \\
D & 3.2 .0 & 14 & 15,31 \\
\hline
\end{tabular}

Fonte: Pesquisa direta.

Para a contagem de termotolerantes e Escherichia coli foram encontrados os seguintes resultados que foram descritos na tabela 4:

Tabela 4: Contagem de termotolerantes e Escherichia coli realizado em caldo E. coli, considerando (+) positivo e (-) negativo para formação de gás.

\begin{tabular}{cccc}
\hline Amostra & $\begin{array}{c}\text { Combinação de } \\
\text { Tubos + }\end{array}$ & NMP/g & Resultado \\
\hline A & 1.1 .0 & 7,4 & 10,45 \\
B & 2.1 .0 & 15 & 11,35 \\
C & 3.2 .0 & 14 & 15,31 \\
D & 3.2 .0 & 14 & 15,31 \\
\hline
\end{tabular}

Fonte: Pesquisa direta.

$\mathrm{Na}$ contagem total de aeróbios mesófilos em placas, foram contados os crescimentos de colônias bacterianas de acordo com a tabela 5 .

Tabela 5: contagem total de aeróbios mesófilos em placas, valores médios da triplicata.

\begin{tabular}{crcc}
\hline Amostra & $\mathbf{1 0 -}^{\mathbf{1}}$ & $\mathbf{1 0 -}^{\mathbf{2}}$ & $\mathbf{1 0 -}^{\mathbf{3}}$ \\
\hline $\mathbf{A}$ & $>300$ & 5 & - \\
B & 228 & 168 & 12 \\
$\mathbf{C}$ & $>300$ & 250 & 24 \\
$\mathbf{D}$ & $>300$ & 235 & 20 \\
\hline
\end{tabular}

Fonte: Pesquisa direta.

Para análise das amostras quanto a presença de Salmonella spp, no meio de cultura XLD as amostras A e D não cresceu colônias sugestivas para a Salmonella, enquanto as amostras B e C cresceram colônias enegrecidas sugestivas para Salmonella spp. Para os meios de cultura SS e HE, foram encontradas colônias enegrecidas nas amostras B e C para os dois meios, as demais amostras cresceram amostras não características.

Já para a pesquisa de Staphylococcus spp. todas as amostras continham colônias sugestivas para essa bactéria. Quanto a presença de bolores e leveduras foi detectada a presença de leveduras nas amostras A, B e D. No entanto na pesquisa para Clostridium spp. houve crescimento em todas as amostras, porém nenhuma colônia era característica da bactéria e quando foi realizado a coloração de Gram foi detectado que as mesmas apresentaram morfologia de cocos Gram+e outras bacilos Gram.

As colônias resultantes de todas as metodologias foram isoladas em meio de cultura TSA para em seguida ser realizado os testes bioquímicos onde para as amostras submetidas a pesquisa de coliformes totais foram encontradas os seguintes gêneros: amostra A foi encontrada a presença de E. coli e Klebisiella spp., para a amostra B, encontrouse Klebisiella spp., na amostra C, Klebisiella spp., Shiguella spp. e Enterobacter spp., já a amostra D, foi encontrada a presença de E. coli, Shiguella spp., Enterobacter spp., e Kelbisiella 
spp. Para a pesquisa para Staphylococcus spp. todas as amostras foram positivas.

$\mathrm{O}$ resultado da pesquisa para a avaliação da farinha de carne e ossos, mostram que é necessário a adoção de boas práticas de fabricação dos produtos de origem animal, mesmo que os alimentos originados sejam para consumo animal (VALLIN et al., 2009). Assim, as indústrias de rações devem organizarem-se no sentido de melhorar o setor, evitando diversos tipos de contaminações, aumentando a qualidade das rações, principalmente aquelas de origem animal, pois são de fácil contaminação com resíduos do ambiente (BELLAVER, 2001).

Alguns resíduos podem compor as farinhas, porém em relação a digestibilidade, essa pode ter alterações dependendo do conteúdo dos resíduos, por isso a adição de pêlos, pó de chifre, conteúdo gastrointestinal são adulterações na composição desses alimentos. Todos os ingredientes da ração estão sujeitos à contaminação. Essa adição ocorre devido à falta de fiscalização rigorosa. Outras adulterações também podem ocorrer, principalmente adição de calcário e uréia (SARTORELLI, 1998).

Os ingredientes da ração animal são bastante susceptíveis a contaminação por coliformes totais e Salmonellas, principalmente as farinhas devido sua baixa atividade de água, essa característica mantém as células bacterianas desidratadas, porém viáveis (DAVIES et al., 2004).

A alta incidência de micro-organismos encontrados nesta pesquisa, sugere que essa produção de farinha não foi realizada de acordo com as boas práticas de fabricação ou que as condições de armazenamento dessas rações não foram adequadas. Assim, pode influenciar na qualidade microbiológica da mesma (GABBI \& CYPRIANO, 2011).

$\mathrm{O}$ resultado encontrado mostra que vários micro-organismos foram detectados, isso sugere que cada vez mais a fabricação dessas farinhas seja monitorada dentro do programa de boas práticas de fabricação para detectar a contaminação e evitar a introdução de Salmonella na produção animal, já que de acordo com a legislação, esse patógeno deve estar ausente nas rações. Nessa pesquisa, não foi confirmada a presença dessa bactéria, porém outros agentes foram encontrados (WIERUP \& HÄGGBLOM, 2010).

Quanto a presença de leveduras, esse fato também pode estar associado com o aumento da umidade e temperatura nas embalagens. Esse fato pode ser preocupante, pois pode favorecer a incidência de fungos com capacidade de produção de micotoxinas, o que pode levar a morte do animal (WEINBERG, et al., 2008).

\section{CONSIDERAÇÕES FINAIS}

A inclusão da Farinha de carne e ossos ou a substituição da farinha de peixe por esta, nas rações para peixes, deve ser realizado de forma criteriosa, para que não exceda o valor de minerais, principalmente o cálcio e o fósforo, exigido pela espécie trabalhada.

Foram encontradas Klebisiella spp., Escherichia coli, Shiguella spp., Enterobacter spp., Staphylococcus spp. e leveduras, porém não foi confirmado a presença de Salmonella spp. A presença de coliformes totais na farinha de carne e osso está associada à falta de higiene na fabricação e manipulação da mesma.

Dessa forma há necessidade de monitoramento para uma melhor eficiência desde a fabricação, evitando a inclusão de partes proibidas ou que, em excesso, podem reduzir a qualidade nutricional da farinha, bem como no armazenamento, que pode servir de veículo para contaminação do produto.

\section{REFERÊNCIAS}

ANDRIGUETTO, et al. 1988a, citado por EVANDRO CAMPESTRINI, Farinha de carne e ossos, Revista Eletrônica Nutritime, v.2, $\mathrm{n}^{\circ} 4$, p.221 -234 julho/agosto de 2005.

BELLAVER, C. Ingredientes de origem animal destinados à fabricação de rações In: Simpósio sobre ingredientes na alimentação animal. 2001, Campinas. Anais. Campinas: 2001, p.167-190. 
(VALÉRIO et al., 2016)

BELLAVER, C.; ZANOTTO, D. L.. Parâmetros de qualidade em gorduras e subprodutos proteicos de origem animal. In: CONFERENCIA APINCO DE CIENCIA E TECNOLGIA AVICOLAS, 2004, Santos, SP. Anais. CAMPINAS: FACTA, 2004. v. 1. p. $79-102$

CUSTODIO, D.P., BRANDSTETTER, E. V., OLIVEIRA, I.P., OLIVEIRA, L.C., SANTOS, K.J.G., MACHADO, O.F., ARAUJO, A.A., Ração: Alimento Animal Perecível. Revista Eletrônica Faculdade Montes Belos, v.1, n.2, p. 131 - 147, 2005.

DAVIES, P.R., HURD, H.S., FUNK, J.A., FEDORKA-CRAY, P.J. \& JONES, F.T. (2004) The role of contaminated feed in the epidemiology and control of Salmonella enteric in Pork Production. Food bourne Pathogens and Disease. v.1, n.4, 202-15.

GABBI, A.M., CYPRIANO, L. Aspectos microbiológicos e fisico-químicos de três rações comercias sob diferentes condições de armazenamento. Rev. Bras. Saúde Prod. An. v. 12, n.3, p.784-793, 2011.

GOMES, L.C.; CHAGAS,E.C.; MARTINSJUNIOR, H.; ROUBACH, R.; ONO, E.A.; LOURENÇO, J.N.P. Cage culture of tambaqui (Colossoma macropomum) in a central Amazon floodplain lake. Aquaculture, v. 253, p.374-384, 2006.

PAIVA, K.C. Utilização de ração a base de sorgo na alimentação de tilápia do Nilo (Oreochromis Niloticus) sobre as características zootécnicas do peixe e características físicas, químicas, bioquímicas, histomorfológicas viscerais e sensoriais do filé. 2011. 51f. Dissertação (Mestrado em Ciências). Universidade Federal de Pelotas. Programa de Pós-Graduação em Zootecnia, Pelotas, RS.

ROSTAGNO, H.S. et al. Tabelas Brasileiras para Aves e Suínos: Composição dos alimentos e exigências nutricionais. Viçosa, UFV. 2000. 141p.

SANTOS, L.D.; MEURER, F.; OLIVEIRA, S.T.L.; SOUSA, S.M.N.; SOUZA, R.C. Digestibilidade de ingredientes alternativos do
Semiárido Nordestino em rações peletizadas e extrusadas para tilápia do Nilo. $3^{\circ}$ Simpósio Internacional de Nutrição e Saúde de peixes. FMVZ-UNESP, Botucatu, 2009.

SANTOS, L. D. dos; SOUSA, S. M. de N.; SILVA, L. C. R. da; BOMBARDELLI, R. A.; MEURER, F. Efeitos da peletização e extrusão sobre a digestibilidade de ingredientes alternativos do Semi-árido Nordestino para a tilápia do Nilo. Semana: Ciências Agrárias, Londrina, v. 35, n. 6, p. 3367-3376, nov./dez. 2014

SARTORELLI, S.A.A. Uso de farinha de carne e ossos em rações de frangos de corte. Lavras: UFLA, 1998. 54p. Dissertação (Mestrado em Zootecnia) - Universidade Federal de Lavras, 1998.

SIGNOR, A.A.; SIGNOR, A.; BOSCOLO, W.R.; FEIDEN, A. Farinha de carne e ossos na alimentação de larvas de tilápia do Nilo. Ciência Rural, v.40, n.4, p.970-975, 2010.

VALLIN, V. M; VANERLI, B. BATTAGLINI, A. P. P.; TAMANINI, R.; FAGNANI, R; ANGELA, H. L.; SILVA; L. C. C. Melhoria da qualidade do leite a partir da implantação de boas práticas de higiene na ordenha em 19 municípios da região central do Paraná. Semana: Ciências Agrárias, v. 30, n. 1, p. 181-188, jan./mar. 2009.

VIEITES, F.M. Valores energéticos e de aminoácidos digestíveis de farinhas de carne e ossos para aves. Viçosa: UFV. 1999. 75p. Dissertação (Mestrado em Zootecnia) Universidade Federal de Viçosa, 1999.

WEINBERG, Z.G.; YAN, Y.; CHEN, Y.; FINKELMAN, S.; ASHBELL, G.; NAVARRO, S. The effect of moisture level on high-moisture maize (Zea mays L.) under hermetic storage conditions in vitro studies. Journal of Stored Products Research, v.44, p.136-144, 2008.

WIERUP, M. \& HÄGGBLOM, P. (2010) An assessment of soybeans and other vegetable proteins as source of salmonella contamination in pig production. Acta Veterinaria Scandinavica. 52, 1-9. 